\title{
Estudio diagnóstico sobre la situación, necesidades y demandas de las personas con espina bífida e hidrocefalia y sus familias en la Comunidad Autónoma del País Vasco ${ }^{1}$
}

\author{
Asociación Bizkaia Elkartea Espina Bífida e Hidrocefalia (ASEBI) \\ <info@asebi.es>
}

Euskal Autonomia Erkidegoko bizkar hezur bifidoa duten pertsonen inguruko errealitatearen azterlan eta datuen eskasiari aurre egiteko, 2011an burutu zuen ikerketa bat Bizkaiko Bizkarrezur Bifidoa eta Hidrozefalia Elkarteak (ASEBI), horren bidez ezagutzeko Euskadin egunerokoan gaitz hori duten pertsonen errealitatea. Artikulu honetan jasotzen dira bizkar hezur eta hidrozefaliak eragindako kolektibo horren inguruko ezaugarritzea burutzeko azterlanaren ondorio nagusiak, eta nahi dira identifikatu gaixoen eta berauen familien premiak, horretarako biltzen delarik hezkuntza, lan, aisialdi, partaidetza eta osasunaren inguruko informazioa.

\section{GAKO-HITZAK:}

Bizkar hezur bifidoa, hidrozefalia, ezgaitasuna, premiak, eskariak, EAE.
Ante la falta de estudios y datos sobre la realidad de las personas con espina bífida en la Comunidad Autónoma del País Vasco, en 2011, la Asociación Bizkaia Elkartea Espina Bífida e Hidrocefalia (ASEBI) llevó a cabo una investigación para analizar la realidad a la que se enfrentan en su día a día las personas que viven con esta enfermedad en Euskadi. En este artículo, se recogen las principales conclusiones de ese estudio sobre la caracterización del colectivo de personas afectadas por espina bífida e hidrocefalia, así como la identificación de sus necesidades y la de sus familiares, recopilando para ello información de los ámbitos educativo, laboral, de ocio y tiempo libre, de participación ciudadana o de salud.

\section{Palabras Clave:}

Espina bífida, hidrocefalia, discapacidad, necesidades, demandas, CAPV. 


\section{Planteamiento del estudio}

Para la Asociación Bizkaia Elkartea Espina Bífida e Hidrocefalia (ASEBI), como entidad del tercer sector, promover la investigación sobre la espina bífida es de vital importancia, máxime cuando no hay estudios recientes y ninguno en Euskadi. Es por ello por lo que, en 2011, llevó a cabo una investigación para conocer la realidad a la que se enfrentan en su día a día las personas que viven con esta discapacidad en la Comunidad Autónoma del País Vasco (CAPV).

El conocimiento es un instrumento fundamental para la mejora en todos los órdenes, y de ahí la necesidad de promoverlo. El estudio surgió de una necesidad imperiosa por conocer la situación de las familias y las personas afectadas. Profesionales de ámbitos como el sociosanitario o el educativo se encuentran ante un desconocimiento importante de la realidad de esta discapacidad, el grado en que les afecta a las personas y de cómo afrontar su situación.

Estudios como éste suponen un pilar para entidades como ASEBI, al combinar de forma única la solidaridad, la competitividad y su presencia social. Este trabajo pretendía también apoyar la consolidación y desarrollo del mencionado colectivo, y servir para concienciar y dar más independencia a un número mayor de personas con espina bífida e hidrocefalia.

Por consiguiente, el estudio se abordó desde una perspectiva que proporcionaba conocimiento social, sanitario y educativo. Se trataba de ir descubriendo las claves que permitían revelar a estas personas y sus familias, y acrecentar su valor e imagen positiva, para ajustar su situación actual y poder mejorar su futuro en su desarrollo integral como personas y visualizar sus capacidades antes que sus limitaciones. Esta investigación nos ha permitido contar con información ordenada y sistemática sobre las necesidades, prioridades y demandas de estas personas y sus familias, así como disponer de una herramienta para darnos a conocer mejor ante la sociedad.

\section{2. ¿Qué es la espina bífida?²}

La espina bífida es la malformación congénita más grave compatible con la vida. Se trata de un defecto congénito del tubo neural que consiste en un anormal desarrollo embrionario producido durante la tercera o cuarta semana de gestación, momento en el que se forma el cierre del tubo neural (parte del embrión a partir de la cual se forman el cerebro y la médula espinal) y de sus estructuras adyacentes, que conlleva secuelas crónicas y cuyas causas aún hoy son desconocidas. Como consecuencia de este defecto, la persona presenta discapacidad multiorgánica en diferentes grados.

\footnotetext{
2 Para más información, consúltese 〈http://www.asebi.es〉.
}

Son múltiples las secuelas físicas y psicológicas de la enfermedad. En cuanto a las primeras, la espina bífida afecta, por lo menos, a tres de los sistemas más importantes del organismo (neurológico, locomotor y genitourinario), por lo que será necesario un abordaje bajo la óptica multidisciplinar. En cuanto a las secuelas psicológicas, existen pocos estudios que las hayan investigado en profundidad, pero sí se puede afirmar que la falta de aceptación por parte de la sociedad, la familia o los compañeros/as de las limitaciones de estas personas afectadas es la causa más importante del aislamiento y la falta de una vida normalizada y en igualdad de oportunidades que padecen las personas con espina bífida.

Si bien su etiología es desconocida y su origen heterogéneo, está científicamente reconocido que la ingesta de folatos o ácido fólico tres meses antes de la gestación previene en un $75 \%$ los defectos del tubo neural.

\section{Delimitación del estudio y objetivos}

Nos resultaba fundamental conocer mejor a las personas que se enfrentan a la realidad de vivir con esta discapacidad y cuantificar el colectivo. Queríamos acercarnos a esta realidad desde una perspectiva holística, que abarcara distintos ámbitos de la vida, como la educación, el trabajo, el ocio, las relaciones sociales o la salud. Ello nos debía permitir también conocer en profundidad la visión que, sobre su propia situación, tienen las personas afectadas y sus familiares; e igualmente, elaborar herramientas para poder trabajar con estas personas y ofrecerles la oportunidad de conseguir un futuro mejor en la compleja urdimbre de las relaciones humanas, poniendo el énfasis en la normalidad, no en la normalidad de la uniformidad, sino en aquella que cae dentro del amplio rango de las diferencias individuales. Esta visión no permitía, en suma, adquirir información útil para mejorar tanto los servicios ofertados por ASEBI y otros agentes como para proponer la creación de nuevos servicios o prestaciones dirigidas a las de personas con espina bífida e hidrocefalia y sus familias.

Concretamente, los objetivos específicos marcados para la investigación eran los siguientes:

1. Conocer el perfil sociodemográfico de las personas afectadas y sus familias.

2. Describir la realidad de estas personas afectadas en cada uno de los ámbitos más significativos, identificando sus dificultades reales.

3. Identificar las necesidades no cubiertas o respuestas inadecuadas ofertadas en los ámbitos social, educativo, sanitario, laboral y de ocio/ cultural.

4. Identificar propuestas de mejora de los recursos y prestaciones existentes en ámbitos citados.

5. Conocer la visión del colectivo de familiares de personas afectadas por espina bífida e identificar posibles necesidades. 


\section{Metodología}

La Encuesta de Discapacidades, Autonomía Personal y Dependencia realizada por el Instituto Nacional de Estadística en colaboración con el Ministerio de Sanidad y Política Social en 2008, computó en el País Vasco un total de 496 personas mayores de 6 años con espina bífida e hidrocefalia, lo que supone una tasa de prevalencia de la espina bífida de 2,5 casos por cada 10.000 habitantes.

En nuestro estudio, se tomó en consideración un universo poblacional de 132 personas, de las cuales 64 eran mujeres y 68 hombres, con edades comprendidas entre los 16 y los 40 años (Tabla 1). Estas personas se extrajeron de 152 unidades familiares, con alguno de sus miembros afectados de espina bífida e hidrocefalia. La diferencia entre el número de personas afectadas y el de unidades familiares se debe a que, para el cómputo de estas últimas, se consideraron a todas las familias con algún miembro afectado de espina bífida e hidrocefalia, independientemente de su edad, si bien las personas afectadas de espina bífida e hidrocefalia menores de 16 años no fueron objeto de estudio. Es importante aclarar, además, que únicamente se remitió un cuestionario por familia, de ahí que los datos se desagreguen por sexos.

Tabla 1. Población objeto de estudio (feb. 2011)

\begin{tabular}{l|c|c|c|c}
\cline { 2 - 5 } & Edad & Mujeres & Hombres & Total \\
\hline $\begin{array}{l}\text { Personas } \\
\text { afectadas }\end{array}$ & $\geq 16$ años & 64 & 68 & 132 \\
\cline { 2 - 5 } & $\leq 16$ años & 8 & 12 & 20 \\
\hline Familias & - & - & - & 152 \\
\hline
\end{tabular}

Fuente: Asociación Bizkaia Elkartea de Espina Bífida e Hidrocefalia (2012).

Se partió de una concepción de las personas objeto de estudio como agentes activos durante el proceso de investigación, lo que se conoce por investigación participativa. De hecho, fueron las personas afectadas y sus familiares pertenecientes a la asociación, en colaboración con personal técnico, quienes pautaron las directrices de la investigación (grupo motor) y quienes participaron en el análisis de su propia realidad. De esta forma, pasan de ser 'objeto' de estudio a sujeto protagonista de la investigación, controlando e interactuando a lo largo del proceso investigador. Ello requiere la implicación y la convivencia del equipo investigador externo con la 'comunidad' a estudiar. Este método de estudio y acción busca obtener resultados fiables y útiles para mejorar situaciones colectivas

La investigación ha combinado la metodología cuantitativa y la cualitativa. La metodología cuantitativa, mediante una encuesta escrita autoadministrada dirigida tanto a las familias como a las personas afectadas, ha permitido ofrecer una pequeña radiografía de la situación, reflejando en datos aquellos aspectos cuantificables. Por su parte, la metodología cualitativa, mediante la celebración de los grupos de discusión, nos ha permitido profundizar en los diagnósticos de las personas afectadas y de sus familias, entenderlas e interpretar los significados intersubjetivos de sus ideas. Además, se llevó a cabo una revisión documental para contextualizar el análisis y orientar la interpretación.

\subsection{Revisión documental}

A través del vaciado de bibliografía ${ }^{3}$ sobre discapacidad física en general, se consiguió profundizar en los diferentes aspectos que se trabajaron a lo largo del informe, así como en la construcción del cuestionario y los grupos de discusión. Por otro lado, permitió establecer un marco de referencia que mostrara el panorama general actual, es decir, situar el contexto de la investigación y constituir el soporte a partir del cual iniciar la reflexión.

\subsection{Encuesta}

Para la recogida de información cuantitativa, se emplearon dos cuestionarios, uno para familiares y otro para personas afectadas, ya que la intención era recabar datos desde las dos visiones. Los cuestionarios fueron diseñados por el Servicio de Investigación Social de Fundación EDE, en contraste permanente con el equipo directivo y técnico de ASEBI, y constaban de 37 preguntas en el caso de familiares y de 77 en el caso de personas afectadas. Estos cuestionarios se distribuyeron por diferentes medios en noviembre de 2011 y se dio de plazo para que lo cumplimentasen hasta mediados de enero de 2012.

Tomando en consideración los datos poblacionales que se recogen en la Tabla 1, las respuestas obtenidas suponen un índice de participación del $47 \%$ de las personas afectadas y del $40 \%$ de las familias. Con todo, el tamaño de la muestra representa -considerando un nivel de confianza del $95 \%$ - un error muestral de $\pm 9,1 \%$ en los datos referidos a las personas afectadas y de $\pm 9,7 \%$ en las familias. Aunque la mayor parte de las respuestas obtenidas correspondían a las personas que integraban la asociación de Bizkaia -que aportaba el $95 \%$ de las respuestas en el caso de las personas afectadas y el $91 \%$ en el de las familias-, los datos pueden considerarse representativos de toda la CAPV, ya que el peso de esta asociación con respecto a la de Araba y Gipuzkoa es mucho mayor, tanto en lo relativo al volumen de personas asociadas como a la intensidad de su actividad.

\subsection{Grupos de discusión}

Para la recogida de información cualitativa, se celebraron dos grupos de discusión, con familiares, por un lado, y con personas afectadas, por otro, lo que permitió enriquecer el análisis, así como explicar, matizar, concretar y comprender algunos de los datos

${ }^{3}$ La bibliografía utilizada puede consultarse al final del artículo. 
que arrojaban las encuestas. A la hora de seleccionar a familiares y personas afectadas que pudieran participar, se realizó un muestreo de tipo opinático en el que el equipo técnico de ASEBI seleccionó a aquellas personas que, por su mayor conocimiento 0 significatividad en la asociación, fueron consideradas más idóneas.

Al grupo de familiares asistieron nueve personas -ocho mujeres y un hombre-. Concretamente, se trataba de seis madres, un padre y otras dos mujeres con grado de parentesco de primer grado. Seis personas eran de Bizkaia y el resto, de Álava/Araba. Si bien la participación fue desigual, la valoración fue positiva, especialmente en lo concerniente a las dinámicas centradas en las preocupaciones y necesidades de las familias, que dieron más pie a la reflexión y debate que las relativas a la actividad de la asociación.

Al grupo de personas afectadas asistieron otras nueve personas -siete mujeres y dos hombres-, con edades comprendidas entre los 20 y los 47 años. Ocho eran de Bizkaia y una, de Araba. En líneas generales, la participación fue correcta en todos los casos, si bien no demasiado crítica. Gracias al debate, se pudieron recoger nuevas aportaciones con respecto a las extraídas de los cuestionarios y profundizar en otras cuestiones.

\section{La realidad de la espina bífida y la hidrocefalia en la CAPV}

\subsection{Perfil sociodemográfico de las personas con espina bífida e hidrocefalia}

Con el objetivo de realizar un perfil de las personas afectadas, se ha analizado una serie de variables sociodemográficas, tales como el sexo, la edad, el estado civil, el número de hijos e hijas, los estudios finalizados, la ocupación y los ingresos. La distribución en cuanto a sexos era bastante simétrica: el $55 \%$, mujeres; y el $45 \%$, hombres. Por edades, el grupo mayoritario era el de quienes tenían entre 25 y 34 años, seguidos del correspondiente a la siguiente franja de edad, de 35 a 44 años. Por tanto, la mitad de las personas consultadas tenían entre 25 y 45 años, siendo la edad media de 30,7 años.

Una amplia mayoría (87\%) de las personas consultadas estaban solteras. Casi en su totalidad, convivían con sus dos progenitores y con un/a hermano/a. En el $44 \%$ de los casos, las viviendas no se encontraban del todo adaptadas a las necesidades de las personas con espina bífida e hidrocefalia. Aunque a prácticamente la mitad les gustaría independizarse, lo veían poco probable a corto plazo, principalmente por cuestiones económicas. La mayoría de los afectados de entre 18 y 24 años tenían estudios secundarios o profesionales, mientras que en la población de la CAPV de entre 20 y 24 años ese porcentaje alcanzaba el $50 \%$. Además se observa que el porcentaje de personas universitarias con espina bífida era sensiblemente menor que el de la población en general para la misma edad.

En lo que se refiere a actividad laboral, prácticamente no había diferencias entre las personas con espina bífida y la población en general hasta los 24 años, ya que el $73 \%$ de las personas con espina bífida e hidrocefalia de entre de 18 a 24 años (15 casos) se encontraban inactivas (incluyendo a las personas que estudiaban), y ese porcentaje era del $70 \%$ para la población en general. Sin embargo, en la franja de edad que va de los 25 a los 44 años (30 casos) sí se aprecian diferencias. Se observa que el porcentaje de personas activas con la enfermedad era sensiblemente menor que el de la población en general para la misma edad: del $59 \%$ entre las personas con espina bífida e hidrocefalia, y del $88 \%$ entre la población en general.

De hecho, tal y como se muestra en la Tabla 2, el $39 \%$ de las personas afectadas estaban ocupadas, cuando el porcentaje era del $77 \%$ en el caso de la población general. El hecho de que el volumen de personas inactivas sea tan elevado ( $41 \%$ ) en esta franja de edad y en la siguiente (del 62\%) nos alerta del problema de la inserción laboral.

Tabla 2. Personas afectadas encuestadas, según actividad y edad (\%)

\begin{tabular}{l|c|c|c|c|c}
\cline { 2 - 6 } & \multicolumn{2}{|c|}{ Total } & \multicolumn{3}{c}{ Distribución por edad } \\
\cline { 2 - 7 } & $\mathbf{F i}$ & $\%$ & $\mathbf{1 8 - 2 4}$ & $\mathbf{2 5}-44$ & $\geq \mathbf{4 5}$ \\
\hline Activos/as & 24 & 40 & 27 & 59 & 38 \\
\hline Ocupados/as & 13 & 22 & 0 & 39 & 25 \\
\hline Parados/as & 11 & 18 & 27 & 20 & 13 \\
\hline $\begin{array}{l}\text { Inactivos/as (incluye } \\
\text { estudiantes) }\end{array}$ & 37 & 60 & 73 & 41 & 62 \\
\hline Total & 61 & 100 & 100 & 100 & 100 \\
\hline
\end{tabular}

Fuente: Asociación Bizkaia Elkartea de Espina Bífida e Hidrocefalia (2012).

En cuanto a los ingresos propios, la mayoría procedían fundamentalmente de prestaciones contributivas relacionadas con la discapacidad, dinero que se aportaba a la economía familiar, pero que las personas afectadas no gestionaban directamente. Los datos reflejan una realidad complicada para las familias en la mayoría de los hogares: por un lado, veían reducido el nivel de ingresos al no obtener recursos a través de las personas con espina bífida, y por otro, los gastos derivados de la atención especial de las personas afectadas oscilaban entre los $100 \mathrm{y}$ 300 euros mensuales, sin contar el material ortoprotésico. Prácticamente la mitad de los hogares recibían algún tipo de prestación o ayuda económica por el cuidado de la persona con espina bífida, y cerca del $40 \%$, la prestación por hijo o hija a cargo. En general, las ayudas que ofrecía la Administración a las familias que tenían entre sus miembros a una persona afectada -la tarjeta de aparcamiento 
y los precios reducidos en los transportes públicos, principalmente- eran calificadas por aquéllas de insuficientes, y a veces, de inadecuadas.

\subsection{Características del hogar}

Tal y como se ha hecho en el análisis de las y los familiares, resulta interesante conocer la composición y características del hogar de las personas afectadas. En este sentido, casi siete de cada diez $(65 \%)$ formaban parte de un hogar en el que residía una pareja con uno o varios hijos o hijas, y algo más de una de cada diez vivía en un hogar compuesto por una pareja sin hijos o hijas (13\%), o en un hogar unipersonal (11\%). Habitualmente los hogares estaban formados por tres o cuatro miembros, siendo 3,17 personas la media de miembros por hogar. En un $10 \%$ de los hogares residían más de una persona con espina bífida.

Tal y como se muestra en la Tabla 3, las familias estaban muy de acuerdo con la importancia del apoyo de toda la familia para sobrellevar las situaciones que derivaban de la enfermedad; además, a pesar de considerar satisfactorias las relaciones familiares eran reacias a admitir posibles disfunciones en las relaciones tanto de pareja como intrafamiliares. Si bien a tenor de estos datos se podría pensar que, en general, el cuidado y atención a la persona afectada no habían erosionado las relaciones familiares, el equipo directivo y técnico de ASEBI disiente en este punto, al considerar, por el contrario, que las consecuencias del cuidado sí erosionan las relaciones de pareja de los progenitores e influye en la falta de desarrollo evolutivo de la persona afectada, como se ha podido constatar en la atención y asistencia del servicio de apoyo psicológico y en los grupos de autoayuda.

No obstante, tal y como se entrevé en las respuestas, existían una serie de preocupaciones en torno a la enfermedad. A la inmensa mayoría de los padres y las madres les preocupaba el futuro de su hijo o hija: concretamente, al $62 \%$ les preocupaba en gran medida qué sería de ellos y ellas cuando ya no pudieran atenderlos ('si yo faltara, las cosas para él/ ella serían muy complicadas'), y sólo el $38 \%$ reconoce 'preocuparse demasiado y sobreprotegerlo/a'. El resto de preocupaciones que tenían que ver con el aspecto emocional, si bien no resultan mayoritariamente compartidas, sí obtienen porcentajes de respuesta considerables que han de tenerse en cuenta: el $31 \%$ reconocía que la enfermedad había generado conflictos dentro de la familia; el $23 \%$, que a menudo se sentía desanimado/a; y el $18 \%$, que su relación de pareja se resentía al tener que encargarse del cuidado de la persona afectada.

\subsection{La salud y la dependencia}

La espina bífida es considerada una enfermedad polideformante, con afectación de múltiples órganos como consecuencia de la patología neurológica que presenta. Esto supone que no todas las personas afectadas padecerán las mismas consecuencias, por lo que resulta de gran relevancia conocer el tipo de lesión concreta que padece cada persona. La mayoría presentaba espina bífida con hidrocefalia, en 7 de cada 10 casos era mielomeningocele, siendo lo más frecuente que la lesión se localizara en la región lumbosacra. Casi la mitad tenía reconocido un grado de minusvalía igual o superior al $75 \%$ y un grado de dependencia II y nivel I; la mitad de las personas encuestadas necesitaban utilizar silla de ruedas.

Las complicaciones derivadas eran múltiples: 6 de cada 10 tenían problemas en la vejiga; 4 de cada 10 no controlaban los esfínteres y, de ellas, 7 de cada 10 utilizaban pañales. Además, casi un $50 \%$ necesitaba sondaje diario ( 4,5 sondajes diarios de media) y 3 de cada 10 sufrían habitualmente de infecciones de orina, por lo que tenían afectados los riñones y necesitaban medicarse con cierta frecuencia. Prácticamente todos sufrían problemas de estreñimiento (por lo que necesitaba medicación) y 3 de

Gráfico 1. Grado de acuerdo con afirmaciones sobre la familia (puntuación media en una escala de o a 10)

El apoyo de la familia es fundamental para sobrellevar la situación derivada de la EBH

Mis relaciones familiares son satisfactorias

Me preocupa el futuro, si yo faltara las cosas para él/ ella serían complicadas

Me preocupo demasiado y lo/la sobreprotejo

A menudo me encuentro desanimado/a

La EBH ha generado conflictos dentro de la familia

Mi relación de pareja se resiente al tener que encargarme del cuidado de la persona afectada por EBH

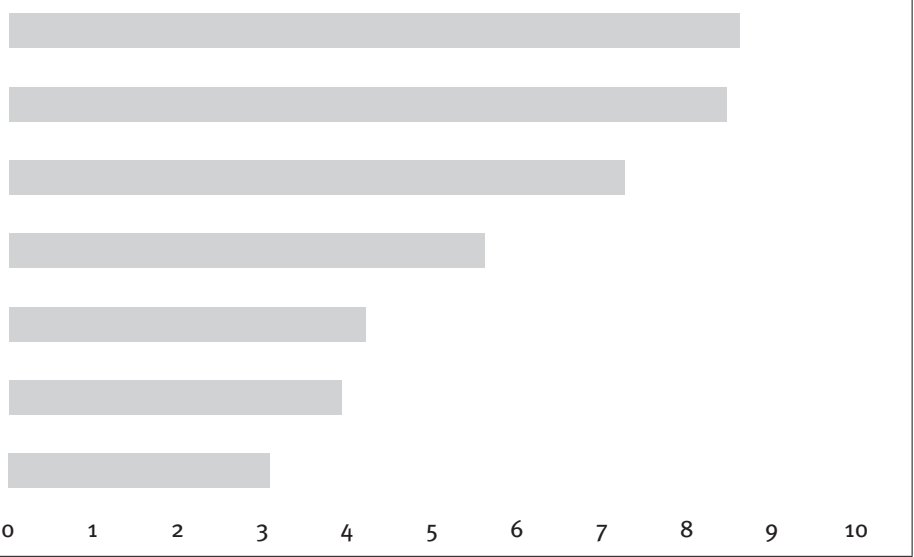

EBH: espina bífida e hidrocefalia. Fuente: Asociación Bizkaia Elkartea de Espina Bífida e Hidrocefalia (2012). 
cada 10 tenían alergia al látex. De cada 10 personas afectadas, 7 necesitaban hacerse controles médicos de manera regular (que se realizaban, en el $30 \%$ de los casos, en el Hospital Universitario de Cruces). Los especialistas más visitados eran los de Urología/ Nefrología, Traumatología, Atención Psicológica o Salud Mental, y Rehabilitación. En este ámbito, las familias mostraban una serie de preocupaciones, ya que consideraban que, en la medida en que mejorara cada uno de los aspectos relacionados con la salud, también lo hacía la calidad de vida de las personas afectadas, que era para todos y todas ellas lo más importante.

Dicho lo anterior, los familiares mencionaban dos preocupaciones por encima de todo. En primer lugar, la relativa a las complicaciones derivadas de la enfermedad -entendiendo por tales las infecciones, las complicaciones en la válvula y en los riñones, o los riesgos derivados de las múltiples operaciones, entre otras-. Y en segundo lugar, la degeneración de la enfermedad -su evolución-. Este asunto provocaba gran preocupación, ya que ponía de manifiesto la necesidad de ayuda permanente (actual y futura) de la mayoría de las personas con espina bífida. Además, en la medida en que padres y, sobre todo, madres (principales cuidadoras) se hacían mayores, la preocupación aumentaba, ya que percibían de manera más cercana las consecuencias de su ausencia y temían la falta de autonomía de su familiar ("que no se valga por ella misma”, "que necesite más ayuda”).

Otra de las cuestiones de gran relevancia para las familias tiene que ver con las secuelas psicológicas que la enfermedad puede acarrear como consecuencia de las dificultades y obstáculos que se le plantean a la persona afectada. Más allá de las consecuencias físicas, nos interesaba indagar en las consecuencias psicológicas. Según la literatura consultada, no parece que la enfermedad en sí misma sea la causa directa de los problemas socioemocionales, sino que más bien, se deben a la respuesta de la sociedad ante la discapacidad y a cómo las personas afectadas gestionan esa respuesta. Por ello, preguntamos a las personas que padecían espina bífida sobre su estado de ánimo, pidiéndoles que mostraran su grado de acuerdo con una serie de afirmaciones, cuyos resultados mostramos en el Gráfico 2.

Por lo general, las personas afectadas se sentían bien consigo mismas (7 puntos de media sobre 10), aunque no gozaban de demasiada autoestima (6 puntos sobre 10). A pesar de ello, eran contrarias a mostrar el lado más negativo de la enfermedad y la mayoría no se sentían reconocidas en frases como 'muchas veces me siento con el ánimo deprimido, solo o poco aceptado', o ‘tengo problemas para conciliar el sueño' (Tabla 3 ).

Tabla 3. Grado de acuerdo afirmaciones relacionadas con el estado de ánimo

\begin{tabular}{l|c|c|c|c|c|c|c|c}
\cline { 2 - 8 } & \multicolumn{2}{c|}{ Desacuerdo } & \multicolumn{2}{|c|}{ Indiferencia } & \multicolumn{2}{c|}{ De acuerdo } & \multicolumn{2}{c}{ NS/NC } \\
\cline { 2 - 8 } & Fi & $\%$ & Fi & $\%$ & Fi & $\%$ & Fi & $\%$ \\
\hline $\begin{array}{l}\text { Me siento } \\
\text { bien conmigo } \\
\text { mismo/a }\end{array}$ & 10 & 16 & 12 & 19 & 39 & 63 & 1 & 2 \\
\hline $\begin{array}{l}\text { Tengo } \\
\text { ataques de } \\
\text { ansiedad y/0 } \\
\text { angustia }\end{array}$ & 42 & 68 & 9 & 15 & 6 & 10 & 5 & 8 \\
\hline $\begin{array}{l}\text { Tengo buena } \\
\text { autoestima } \\
\text { (buen } \\
\text { concepto de } \\
\text { mímismo/a) }\end{array}$ & 11 & 18 & 14 & 23 & 34 & 55 & 3 & 5 \\
\hline $\begin{array}{l}\text { Muchas veces } \\
\text { me siento } \\
\text { con el ánimo } \\
\text { deprimido }\end{array}$ & 28 & 45 & 15 & 24 & 16 & 26 & 3 & 5 \\
\hline $\begin{array}{l}\text { Tengo } \\
\text { problemas } \\
\text { para conciliar } \\
\text { el sueño }\end{array}$ & 36 & 58 & 8 & 13 & 14 & 23 & 4 & 6 \\
\hline $\begin{array}{l}\text { Me siento } \\
\text { solo/a y poco } \\
\text { aceptado/a }\end{array}$ & 32 & 52 & 14 & 23 & 11 & 18 & 5 & 8 \\
\hline
\end{tabular}

Fuente: Asociación Bizkaia Elkartea de Espina Bífida e Hidrocefalia (2012).

Gráfico 2. Grado de acuerdo con afirmaciones relacionadas con el estado de ánimo (puntuación media en una escala de o a 10)

Me siento muy bien conmigo mismo/a

Tengo buena estima (un buen concepto de mí mismo/a)

Muchas veces me siento con el ánimo deprimido

\begin{tabular}{|}
\hline Me siento solo/a y poco aceptado/a \\
\hline Tengo problemas para conciliar el sueño \\
\hline Tengo ataques de ansiedad o angustia
\end{tabular}

\begin{tabular}{|}
\hline Me siento solo/a y poco aceptado/a \\
\hline Tengo problemas para conciliar el sueño \\
\hline Tengo ataques de ansiedad o angustia
\end{tabular}

\begin{tabular}{|}
\hline Me siento solo/a y poco aceptado/a \\
\hline Tengo problemas para conciliar el sueño \\
\hline Tengo ataques de ansiedad o angustia
\end{tabular}
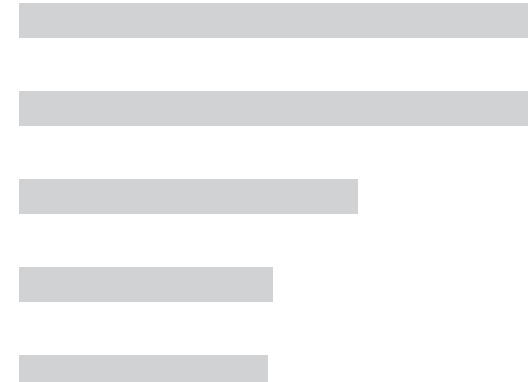

Fuente: Asociación Bizkaia Elkartea de Espina Bífida e Hidrocefalia (2012). 
Con todo, si nos detenemos en los porcentajes recodificados (de o a 3, 'en desacuerdo'; de 4 a 6 , 'indiferente'; y de 7 a 10 , 'de acuerdo'), observamos que un $18 \%$ creía que no tenía buena autoestima y un $16 \%$ no se sentía bien consigo mismo/a. De hecho, un $26 \%$ muchas veces se sentía con el ánimo deprimido, un $23 \%$ tenía problemas para conciliar el sueño y un $18 \%$ se sentía solo/a o poco aceptado/a (Tabla 3).

\subsection{Educación}

Casi la mitad de las personas afectadas consultadas se encontraban estudiando y, a través de los grupos de trabajo, se constató que les suponía un esfuerzo mayor que para el resto, y no precisamente por las barreras arquitectónicas, sino porque el sistema educativo formal "no está pensado para todas las personas, sino para algunas”, las que entran dentro de los parámetros estándar.

Las dificultades comenzaban con las relaciones entre los iguales -que eran crueles en muchos casos ("me han hecho la vida imposible", "me han quitado la silla de ruedas")- y con el profesorado. Se ponen de relieve las dificultades de los centros para aceptar la diversidad en las aulas. Las personas afectadas consideraban que el profesorado, en muchas ocasiones, no contaba con la información y la formación suficiente para enfrentarse a esta realidad en el aula. Unas veces sobreprotegía, y otras pedía demasiado ("el de gimnasia me exigía que diera tantas vueltas en tantos minutos, y yo no podía, y él erre que erre..."). Tanto para las familias como para las personas afectadas, una de las mayores preocupaciones era poder acabar sus estudios. Les preocupaba no poder alcanzar un nivel de formación alto para optar a puestos de trabajo cualificados.

\subsection{Empleo}

El empleo es considerado en la sociedad un elemento esencial de integración y desarrollo personal. Es indispensable para poder llevar a cabo una vida lo más normalizada posible, ya que asegura el desarrollo de capacidades intelectuales y sociales para conseguir la integración en la sociedad.

En relación con el empleo, un $21 \%$ de las personas con espina bífida consultadas estaban ocupadas (el $19 \%$ por cuenta ajena y el $2 \%$ por cuenta propia), un $18 \%$ en situación de desempleo (buscando trabajo) y el restante $16 \%$ estaba inactiva. Concretamente, el $64 \%$ de las que estaban en desempleo habían tenido trabajo anteriormente, y el restante $36 \%$, no. Además, el $50 \%$ de las personas que estaban inactivas nunca habían trabajado (si bien los datos se refieren únicamente a 5 casos). Por lo tanto, nos encontramos con un porcentaje considerable (36\%) de personas en desempleo que nunca antes habían estado empleadas. Estos datos ponen de manifiesto una realidad complicada en lo que a inserción laboral de las personas con espina bífida se refiere. Entre quienes se encontraban en desempleo y buscaban empleo (el $18 \%$ del total de las personas afectadas), la mayoría llevaban buscando empleo más de un año (64\%), y un $18 \%$, menos de un año (otro tanto no respondió a la pregunta) [Tabla 4].

Tabla 4. Tiempo buscando empleo

\begin{tabular}{l|c|c}
\cline { 2 - 3 } & Fi & $\%$ \\
\hline Entre 3 y 6 meses & 1 & 9 \\
\hline Entre 6 meses y un año & 1 & 9 \\
\hline Más de un año & 7 & 64 \\
\hline NS/NC & 2 & 18 \\
\hline Total & 11 & 100 \\
\hline
\end{tabular}

Fuente: Asociación Bizkaia Elkartea de Espina Bífida e Hidrocefalia (2012).

Estas mismas personas se mostraban relativamente pesimistas en relación a su futuro laboral. El $27 \%$ creía que le sería difícil encontrar trabajo pronto, el $18 \%$ pensaba que era imposible que una persona con discapacidad encontrara trabajo en una empresa privada (si bien la mayoría no estaba de acuerdo con esta afirmación) y el $27 \%$ afirmaba que había trabajos en los que no le habían seleccionado por ser una persona con discapacidad. Con el objetivo de obtener una visión lo más amplia posible de las condiciones laborales y las características del empleo de las personas con espina bífida e hidrocefalia (y dado el escaso porcentaje de personas ocupadas), a la hora de analizar los datos relacionados con estas cuestiones se ha seleccionado a las personas que, independientemente de su situación actual, alguna vez habían tenido un empleo.

El $60 \%$ de quienes trabajaban o habían trabajado alguna vez lo hacían en una empresa privada; el $20 \%$, en la administración pública; el $13 \%$, en una organización del tercer sector; y un $7 \%$ no contestó. En el $33 \%$ de los casos el trabajo se desarrollaba en un centro especial de empleo. Prácticamente la mitad (47\%) llevaba más de 5 años trabajando; un $27 \%$, entre 1-3 años; un $20 \%$, menos de un año; y un $7 \%$, entre 3 y 5 años. En el $40 \%$ de los casos habían firmado contrato indefinido; y en el $27 \%$, por obra o servicio.

Con la intención de conocer las principales dificultades con las que podían encontrarse a la hora de acceder a un trabajo o mantenerlo, a todas las personas que contestaron el cuestionario se les pidió que señalaran, a partir de una batería de dificultades en el ámbito del empleo, las tres más importantes, y que las priorizaran. Una vez debatidas en el grupo de discusión, se determinó que las que más les preocupaban eran:

- El escaso fomento del empleo para personas con discapacidad: consideraban que había pocas ayudas a empresas para fomentar la contratación, y que se debería incrementar el porcentaje mínimo de puestos de trabajo para personas con discapa- 
cidad que, por ley, las empresas están obligadas a cumplir. Detrás de esta valoración, se puede percibir que la mayoría de ellas no aspiraban a un puesto de trabajo en el mercado libre.

- El escaso interés de las empresas por contratar a personas con discapacidad. A esto se le une la opinión de que, por lo general, las empresas huían de las personas con discapacidad, ya que el peso de los estereotipos negativos era muy grande y había muchos prejuicios. Además, se apuntaba que el hecho de que, en la mayoría de los casos, contratar a una persona con discapacidad suponía tener que invertir en adaptar espacios y ello dificultaba aún más que los y las empresarias se animaran a contratarlas. En cuanto al empleo, hay que decir que aunque algunas personas sí señalaban en el cuestionario las dificultades que se desprendían de la búsqueda o el cambio de empleo, al profundizar sobre el tema en el grupo se pudo clarificar que estas cuestiones no se correspondían con las preocupaciones principales de las familias.

- La principal preocupación de las familias se centraba en las dificultades que encontraban las personas afectadas a la hora de acceder y mantener un empleo, pues entendían que acceder a un empleo les permitía ser mucho más autónomas e independientes, si bien reconocían que no tenían muchas oportunidades. Además, y como consecuencia de las dificultades en la habilidad manual que muchas personas afectadas presentaban, algunas familias ponían de manifiesto la necesidad de encontrar un empleo que no fuera manual.

Cabe señalar que había casos en los que las familias reconocían no ver dificultades concretas en este ámbito, al no haberse planteado la posibilidad de que su familiar accediera a un empleo ("no he pensado que pueda tener un trabajo"). En este sentido, hay quien aseguraba confiar más en las ayudas y prestaciones económicas de las que la persona afectada pudiera beneficiarse que en sus oportunidades para acceder a un empleo ("confío más en la pensión de mi hija que en la posibilidad de que encuentre trabajo"). Al hilo de esta cuestión, las familias reflexionaban sobre la obligatoriedad de las empresas grandes de contratar personas con discapacidad y no se mostraban muy optimistas. En cierto modo, consideraban que la medida no cumplía con su objetivo de insertar laboralmente a personas con discapacidad.

\subsection{Relaciones sociales, ocio y tiempo libre}

Las relaciones sociales de las personas con espina bífida son muy limitadas, no suelen tener cuadrilla de amigos habitual y las salidas suelen ser esporádicas, generalmente con amigos/as de hermanos/ as o de la familia. No obstante, la inmensa mayoría dice pertenecer a una cuadrilla o grupo de amigos y amigas, que está integrada mayoritariamente (y por este orden) por amigos y amigas del colegio, por personas del barrio, y por compañeros y compañeras de

Tabla 5. Frecuencia con la que las personas afectadas realizaban determinadas actividades de ocio y tiempo libre

\begin{tabular}{|c|c|c|c|c|c|c|c|c|c|c|}
\hline & \multicolumn{2}{|c|}{ Mucho } & \multicolumn{2}{|c|}{ Bastante } & \multicolumn{2}{|c|}{ Poco } & \multicolumn{2}{|c|}{ Nunca } & \multicolumn{2}{|c|}{ NS/NC } \\
\hline & $\mathbf{F i}$ & $\%$ & $\mathrm{Fi}$ & $\%$ & $\mathbf{F i}$ & $\%$ & $\mathbf{F i}$ & $\%$ & $\mathbf{F i}$ & $\%$ \\
\hline $\begin{array}{l}\text { Hacer ejercicio físico en polideportivo o } \\
\text { gimnasio }\end{array}$ & 4 & 6 & 6 & 10 & 21 & 34 & 29 & 47 & 2 & 3 \\
\hline Ir a la piscina o la playa & 2 & 3 & 5 & 8 & 35 & 56 & 16 & 26 & 4 & 6 \\
\hline Practicar deporte adaptado & 2 & 3 & 5 & 8 & 10 & 16 & 41 & 66 & 4 & 6 \\
\hline Acudir a eventos deportivos & 4 & 6 & 12 & 19 & 16 & 26 & 26 & 42 & 4 & 6 \\
\hline $\begin{array}{l}\text { Acudir a eventos culturales (cine, teatro, } \\
\text { conciertos) }\end{array}$ & 3 & 5 & 25 & 40 & 27 & 44 & 4 & 6 & 3 & 5 \\
\hline Ir a la discoteca & 2 & 3 & 10 & 16 & 16 & 26 & 29 & 47 & 5 & 8 \\
\hline $\begin{array}{l}\text { Salir a tomar algo con amistades o comer en } \\
\text { restaurantes }\end{array}$ & 6 & 10 & 37 & 60 & 14 & 23 & 3 & 5 & 2 & 3 \\
\hline Conversar, estar con familiares/conocidos & 23 & 37 & 30 & 48 & 2 & 3 & 2 & 3 & 5 & 8 \\
\hline Pasear & 14 & 23 & 22 & 35 & 13 & 21 & 7 & 11 & 6 & 10 \\
\hline $\begin{array}{l}\text { Ir de excursión (salir al monte, visitar alguna } \\
\text { ciudad) }\end{array}$ & 6 & 10 & 19 & 31 & 25 & 40 & 9 & 15 & 3 & 5 \\
\hline Viajar (dormir fuera de casa) & 4 & 6 & 19 & 31 & 25 & 40 & 11 & 18 & 3 & 5 \\
\hline Ir de compras & 10 & 16 & 24 & 39 & 19 & 31 & 6 & 10 & 3 & 5 \\
\hline Ir a manualidades/talleres & 5 & 8 & 6 & 10 & 10 & 16 & 32 & 52 & 9 & 15 \\
\hline Utilizar Internet y redes sociales & 30 & 48 & 20 & 32 & 3 & 5 & 6 & 10 & 3 & 5 \\
\hline Ver la televisión o películas en DVD & 21 & 34 & 25 & 40 & 11 & 18 & 1 & 2 & 4 & 6 \\
\hline Escuchar música & 24 & 39 & 31 & 50 & 2 & 3 & 2 & 3 & 3 & 5 \\
\hline Leer & 10 & 16 & 19 & 31 & 18 & 29 & 10 & 16 & 5 & 8 \\
\hline
\end{tabular}

Fuente: Asociación Bizkaia Elkartea de Espina Bífida e Hidrocefalia (2012). 
la ASEBI. Por el contrario, un $19 \%$ reconoce no tener cuadrilla. Las actividades de ocio son un elemento socializador de gran importancia para todas las personas, pero si tenemos en cuenta las características del colectivo, cobra más importancia, debido a que dispone de mucho tiempo libre.

El $85 \%$ de las personas afectadas ocupaban parte de su ocio reuniéndose con familiares o personas conocidas; a esta actividad le seguían escuchar música (89\%), ver la televisión o alguna película en DVD (74\%), y salir a tomar algo o a comer en restaurantes (70\%). Además, el $58 \%$ salía con frecuencia a pasear y el $50 \%$ aprovechaba el tiempo para entrar en Internet y las redes sociales. Por otro lado, cabe decir que las personas afectadas consultadas no solían practicar deporte con frecuencia, ni siquiera deporte adaptado. Respecto a los eventos culturales, el $45 \%$ acudía a ellos con mucha o bastante frecuencia, porcentaje muy superior al de la media para el conjunto de la población, en la mayoría de los casos, porque se acudía a dichos eventos en compañía de la asociación.

Por su parte, las familias reconocían que, en líneas generales, las personas afectadas tenían muchas dificultades para las relaciones sociales y uno de los motivos aludidos era el hecho de que "muchos o casi todos los de espina bífida al final tienen ese toque borde", si bien estaban de acuerdo en señalar que ese carácter no era más que un escudo ante las dificultades que debían superar cada día. Al hilo de esta reflexión, algunas personas coincidían en que muchas veces los problemas de autoestima que padecen las personas afectadas están detrás de sus problemas y dificultades para relacionarse.

Además de las dificultades para crear un grupo de amistades, algunas personas ponían de manifiesto los problemas que encontraban a la hora de mantener las relaciones que ya tenían, puesto que no podían acceder a todos los espacios de ocio ("no voy contigo, porque no puedo entrar a esa discoteca"). Parece que, en muchas ocasiones, el ocio y el tiempo libre reforzaban las dificultades que había que superar para mantener la relación ("hay que empujar la silla, le tengo que acompañar a que se sonde...”). En este punto, las familias reflexionaban sobre las diferencias entre "ir o que le lleven", poniendo el acento en que, con las verdaderas amistades, "vas" y no "te llevan".

\section{Propuestas para la mejora de la situación de las personas con espina bífida}

Durante los grupos de discusión, se les pidió que reflexionaran unos minutos sobre la experiencia vivida a lo largo de la enfermedad. En tres paneles, escribieron sus ideas en torno a lo que les indignaba, lo que agradecían y lo que les gustaría. Con ello se pretendió identificar carencias en la atención de las afectadas, pero también conocer las cuestiones que funcionaban correctamente. En la puesta en común de lo señalado a título individual, se tuvo además la oportunidad de concretar y profundizar en cada una de ellas, así como de establecer algunas propuestas para mejorar la situación actual.

En resumen, lo que más indignaba a las personas afectadas era la falta de sensibilización de la sociedad, que obstaculizaba e impedía en gran medida que las personas afectadas pudieran desarrollar una vida normalizada (Cuadro 1).

\begin{tabular}{|l|l|} 
Cuadro 1. Cuestiones que indignaban a las personas \\
afectadas
\end{tabular}

Fuente: Asociación Bizkaia Elkartea de Espina Bífida e Hidrocefalia (2012).

A tenor de sus respuestas, lo que más agradecían las personas afectadas era el apoyo recibido por parte de la familia y las amistades (Cuadro 2).

\begin{tabular}{|l|l|}
\hline \multicolumn{2}{|l|}{$\begin{array}{l}\text { Cuadro 2. Cuestiones que agradecían las personas } \\
\text { afectadas }\end{array}$} \\
\hline Ideas destacadas & Aportaciones literales \\
\hline $\begin{array}{l}\text { Aspectos relacionados } \\
\text { con el entorno más } \\
\text { próximo }\end{array}$ & $\begin{array}{l}\text { "El apoyo de amigos y familia". } \\
\text { "La ayuda". } \\
\text { "La comprensión y ayuda que ofrecen } \\
\text { algunas personas". } \\
\text { "Que piensen en mis limitaciones a la } \\
\text { hora de planificar actividades". } \\
\text { "Tener algún amigo con el que poder } \\
\text { disfrutar". } \\
\text { "El tipo de relación que tengo con } \\
\text { amigos y familiares que no me hacen } \\
\text { sentir diferente". } \\
\text { "Que en clase me traten igual que a los } \\
\text { demás". }\end{array}$ \\
\hline $\begin{array}{l}\text { Aspectos relacionados } \\
\text { con la asociación }\end{array}$ & $\begin{array}{l}\text { "Que me hayan ayudado a ver la vida de } \\
\text { otra manera y de vivirla a mi manera sin } \\
\text { que me afecte". }\end{array}$ \\
\hline $\begin{array}{l}\text { Aspectos relacionados } \\
\text { con la persona afectada }\end{array}$ & "Aceptarme como soy". \\
\hline
\end{tabular}

Fuente: Asociación Bizkaia Elkartea de Espina Bífida e Hidrocefalia (2012). 
Lo que les gustaría principalmente era mejorar sus relaciones sociales y que la sociedad les aceptara tal y como son, así como que se eliminasen por completo las barreras arquitectónicas, y poder ser independientes (tener un trabajo, una vivienda).

\begin{tabular}{|l|l|}
\hline \multicolumn{2}{|l|}{ Cuadro 3. Deseos de las personas afectadas } \\
\hline Ideas destacadas & Aportaciones literales \\
\hline $\begin{array}{l}\text { Aspectos } \\
\text { relacionados con la } \\
\text { accesibilidad }\end{array}$ & $\begin{array}{l}\text { "Que mejoraran o no existieran barreras } \\
\text { arquitectónicas". } \\
\text { "Más accesibilidad". } \\
\text { "Poder acceder a los establecimientos sin } \\
\text { tener que depender de nadie". } \\
\text { "Poder hacer cosas que hacen otros, pero } \\
\text { buscando otra manera". }\end{array}$ \\
\hline $\begin{array}{l}\text { Aspectos } \\
\text { relacionados con la } \\
\text { salud }\end{array}$ & $\begin{array}{l}\text { "Preocuparme menos por la salud". } \\
\text { "Seguir teniendo la calidad de vida } \\
\text { actual". }\end{array}$ \\
\hline $\begin{array}{l}\text { Aspectos } \\
\text { relacionados con el } \\
\text { empleo y la formación }\end{array}$ & $\begin{array}{l}\text { "Tener un trabajo". } \\
\text { "Tener un empleo". }\end{array}$ \\
\hline $\begin{array}{l}\text { Aspectos } \\
\text { relacionados con } \\
\text { la sociedad y las } \\
\text { relaciones sociales }\end{array}$ & $\begin{array}{l}\text { "Que me aceptaran tal y como soy, con } \\
\text { todas las consecuencias". } \\
\text { "Me gustaría que la gente pusiera algo de } \\
\text { su parte". } \\
\text { "Hacer amistades fuera de ASEBI". } \\
\text { "Seguir manteniendo las amistades } \\
\text { actuales". }\end{array}$ \\
\hline $\begin{array}{l}\text { Aspectos } \\
\text { relacionados con la } \\
\text { autonomía }\end{array}$ & $\begin{array}{l}\text { "Acceder a una vivienda". } \\
\text { "Independencia". } \\
\text { "Tener una vivienda". }\end{array}$ \\
\hline
\end{tabular}

Fuente: Asociación Bizkaia Elkartea de Espina Bífida e Hidrocefalia (2012).

Como se ha señalado anteriormente, el grupo de discusión facilitó el establecimiento de una serie de propuestas para la mejora de la situación de las personas afectadas, propuestas que principalmente se dirigían a dos agentes: la Administración y el propio colectivo de personas afectadas por espina bífida.

\section{Conclusiones}

El estudio realizado por ASEBI constituye un referente en cuanto a la identificación y caracterización de las personas con espina bífida en la Comunidad Autónoma del País Vasco, que ha permitido acercar la realidad del colectivo a la sociedad en general y a los y las profesionales que atienden a estas personas en distintos ámbitos, lo que es de suma importancia para el trabajo que hacemos desde las asociaciones de espina bífida. Hemos de mencionar que hemos podido contar con el testimonio de personas valientes, que, a pesar de tantas dificultades, siguen esforzándose día a día.

La reflexión sobre los resultados del proceso investigador llevó finalmente a la evaluación de propuestas de mejora que las familias y las personas afectadas encaminaban a paliar sus principales preocupaciones (la propia Asociacion ha sido objeto de aportaciones concretas para la mejora e incremento de servicios). El conocimiento de la dura realidad cotidiana de las personas afectadas y sus familias nos permitió identificar las necesidades no cubiertas y las posibles mejoras.

Las propuestas (o demandas) dirigidas a la Administración pivotaban, principalmente, en torno a cinco ejes:

- Garantizar la igualdad de oportunidades y la inclusión del colectivo. Éste era, sin lugar a dudas, el mensaje que querían trasladar a la Administración: "que seamos considerados ciudadanos y ciudadanas de pleno derecho", como única vía para ver garantizados todos sus derechos, tener "las mismas oportunidades de realizarnos que el resto" de las personas y "no sentirnos excluidos socialmente".

- Información y sensibilización a la sociedad: se veía prioritario que la Administración no bajara la guardia y dedicara esfuerzos a sensibilizar a la ciudadanía sobre la espina bífida en clave positiva ("ya que no somos una carga"). En este sentido, apuntaban de manera especial a la necesidad de sensibilizar a los y las escolares sobre las discapacidades en general y la espina bífida en particular, en especial en aquellos centros en los que hubiera alumnado con esta enfermedad. Otra cuestión importantísima era informar sobre cómo prevenir la espina bífida, tomando ácido fólico durante las primeras semanas de gestación, ya que es algo muy sencillo y barato.

- Reconocimiento de la espina bífida como enfermedad crónica: ésta era una de las principales reivindicaciones del colectivo de familiares y personas afectadas. Si la espina bífida fuese reconocida como enfermedad crónica, las personas que la padecen podrían optar a una serie de servicios y ayudas a los que ahora no tienen acceso, tales como asistencia médica, prótesis o ayudas técnicas gratuitas, y su situación mejoraría sustancialmente. De esta forma, las familias se verían algo más liberadas de la carga económica que supone la enfermedad.

Demandaban y veían como una necesidad prioritaria la financiación integral de los tratamientos ("se nace y se muere con la misma enfermedad, es crónica”). También había otra petición recurrente: crear un servicio de asesoramiento y acompañamiento integral, multidisciplinar e interdisciplinar, en el que se atendiera a las personas con espina bífida. De esta manera, se reduciría el número de visitas a los diferentes especialistas y se ahorraría tiempo a las familias y afectados, que deben interrumpir sus tareas para acudir a las revisiones de los diferentes especialistas.

Además, se pedía agilizar los trámites burocráticos, hacerlos más sencillos y sobre todo que se resolvieran más rápidamente. También se reclamaban ayudas para el transporte, para independizarse (acceder a una vivienda) y para la inserción laboral, mediante el establecimiento de multas para que se cumpla la Ley de Empleo y mediante ayudas a empresas para la contratación de personas con discapacidad. 
- Eliminación de las barreras arquitectónicas: se reclamaba la adaptación de la vía pública, los establecimientos de ocio, los comercios y el transporte público. Como decían algunas personas, "no se trata sólo de que el del autobús baje la rampa, sino de que no pare en medio de un contenedor de basura, o de una papelera, o de un árbol [...] y de que la gente se dé cuenta, de que no lo tengamos que estar pidiendo... y parezcamos unos bordes".

En cuanto a la adaptación de las viviendas, proponían participar (que se les tuviera en cuenta) en el diseño de las viviendas sociales adaptadas, para garantizar que se amoldan a su discapacidad, y no a la inversa. Sugerían aplicar el diseño universal, de manear que las viviendas respondieran mejor a sus necesidades de movilidad y no se limitaran únicamente a cumplir los parámetros legales. Ligado a lo anterior, se proponía también participar en el diseño de los planes urbanísticos de las ciudades, de modo y manera que urbanistas pudieran atender sus reclamaciones e incorporarlas en sus proyectos. Asimismo, también sugerían rebajar los requisitos de acceso a las viviendas de protección oficial para que más personas con discapacidad pudieran optar a ellas.

- Flexibilización del sistema educativo: les parecía muy importante y necesario normalizar la discapacidad en el sistema educativo, es decir, que no se viera como algo excepcional en un centro escolar, sino como una posibilidad más, y como tal fuera tenida en cuenta y programada. Para que esto ocurriera, consideraban necesario que la Administración competente mejorara el sistema de adaptaciones curriculares y que se flexibilizaran los sistemas educativo y laboral, de forma que una persona afectada "no tuviera que renunciar a estudiar ni a trabajar”, pues son derechos sociales de todas las personas.

Las familias reconocían abiertamente que, como consecuencia de todas las necesidades y cuidados que necesitaban sus hijos e hijas, tendían a sobreprotegerloas/as en exceso, por lo que se mostraban de acuerdo en la necesidad de darles más espacio y tiempo. Aseguraban que los miedos, dudas e incertidumbres que sentían obstaculizaban, en muchos casos, la autonomía de los hijos e hijas. Algunas personas hablaban sobre la necesidad de reeducar, en cierta medida, a los padres y madres.

Por parte del colectivo, se identificaron propuestas de mejora relacionadas con las personas afectadas a título particular. Reconocían la necesidad de hacer mucho trabajo personal y de quererse más. En este sentido, mencionaban la importancia de trabajar la autoestima, y de acudir a terapias y grupos de autoayuda.

La propuesta relacionada con ASEBI se centraba en aumentar y diversificar sus actividades, para que la participación de las personas asociadas aumentara y fueran más protagonistas. El trabajo que desarrolla la asociación no se caracteriza por producir efectos inmediatos o éxitos espectaculares. La claridad de objetivos, la persistencia en el tiempo y la atención a la familia, a la vez que a las personas afectadas, hablan de un colectivo con muchas necesidades en todos los ámbitos y con un futuro poco esperanzador.

Destacado lo anterior, la evaluación realizada también alertaba sobre obstáculos a los que se enfrentaba el colectivo, que defendía sus derechos ante la Administración como uno más, pero no incluía su reto personal de ser uno más con el esfuerzo, el trabajo y la implicación, es decir, de gestionar su propia vida con autonomía y empoderamiento, a la vez que reclamaba ayuda institucional.

A pesar de todo lo que se ha avanzado, en ASEBI consideramos que todavía nos queda mucho más por hacer. Este estudio constituye un punto de partida para seguir trabajando por y para que las personas con espina bífida e hidrocefalia consigan la plena inclusión, ser como uno/a más en la sociedad. 


\section{Bibliografía}

(2008) Boletín del ECEMC. Revista de Dismorfología y Epidemiología, serie V, no 7 [ [http://gesdoc. isciii.es/gesdoccontroller?action=download \& $\mathrm{id}=02 / 08 / 2012-656 \mathrm{e}$ d 54 a9) $)$.

ASOCIACIÓN BIZKAIA ELKARTEA DE ESPINA BÍFIDA E HIDROCEFALIA (2012): Estudio diagnóstico sobre la situación, necesidades y demandas de las personas con EBH y sus familias, Bilbao, Asociación Bizkaia Elkartea Espina Bífida e Hidrocefalia [khttp://www.asebi.es/wpcontent/uploads/2011/10/Estudio-DiagnosticoSituaci\%C3\%B3n-y-Demandas-EBH.pdf`].

ASPAYM MADRID (2002): Guía práctica para lesionados medulares, Madrid, ASPAYM Madrid.

CARRERAS, E. et al. (2012): "Tratamiento prenatal del mielomeningocele”, Diagnóstico Prenatal, vol. 23, n- 4 , págs. 148-153 [khttp://dx.doi. org/10.1016/j.diapre.2012.06.006)].

COMISIÓN EUROPEA (2010): Estrategia Europea sobre Discapacidad (2010-2020): un compromiso renovado para una Europa sin barreras, Bruselas, Comisión Europea, COM(2010) 636 final.

CUXART, A.; e IBORRA, J. (1990): Espina bífida. Secuelas ortopédicas. Principios y consideraciones generales del tratamiento, Gerona, Associació Gironina d'Espina Bifida i/o Hidrocefalia.

DEPARTAMENTO DE ACCIÓN SOCIAL (2010): Plan para la Participación y Calidad de Vida de las Personas con Discapacidad 2010-2013, Bilbao, Diputación Foral de Bizkaia.

EXPÓSITO TIRADO, J. A. et. al. (2002): "Estudio descriptivo de 128 casos de espina bífida paralítica", Rehabilitación, vol. 36, nํ4, págs. 208-214.

FEDERACIÓN ESPAÑOLA DE ASOCIACIONES DE ESPINA BÍFIDA E HIDROCEFALIA (s/d): Investigación sobre la población afectada por espina bífida e hidrocefalia. Resumen ejecutivo, Madrid.

GÓMEZ DE TERREROS, M.; y RODRÍGUEZ FRANCO, L. (1999): "Evaluación psicológica en niños y adolescentes afectos de espina bífida paralítica o mielomeningocele", en LOZANO OYOLA, J. F.; y GÓMEZ DE TERREROS, M. (eds.), Avances en Salud Mental Infanto-Juvenil, Sevilla, Universidad de Sevilla, págs. 151-165.

IMSERSO (2004): Situación, necesidades y demandas de personas con espina bífida e hidrocefalia. Informe de resultados, Madrid, Imserso.

INE (2008): Encuesta de Discapacidades, Autonomía Personal y Dependencia [rhttp://www.ine.es/ jaxi $/$ menu.do?type $=$ pcaxis $\&$ path $=\% 2 \mathrm{Ft} 15 /$ p418\&file $=$ inebase $\& L=0\rangle]$.

JIMÉNEZ RODRIGO, A. (1998): Espina bífida. Aspectos psicológicos, Madrid, Imserso.

MARTíNEZ, S. (1989): “Consideraciones acerca de la espina bífida”, Espina Bífida i/o Hidrocefalia, ํㅜㄴ 5 , págs. 15-16.

MARTíNEZ AGULLÓ, E. (1990): Mielomeningocele: tratamiento urológico, Madrid, Federación Española de Asociaciones de Espina Bífida e Hidrocefalia.

MINISTERIO DE SANIDAD Y POLÍTICA SOCIAL (2009): III Plan de Acción para las Personas con Discapacidad 2009-2012, Madrid, Ministerio de Sanidad y Política Social.

OBSERVATORIO DEL TERCER SECTOR DE BIZKAIA (2010): Libro blanco del tercer sector de Bizkaia / Bizkaiko hirugarren sektorearen liburu zuria, Bilbao, Observatorio del Tercer Sector de Bizkaia [khttp://www.3sbizkaia.org/Archivos/ Documentos/Enlaces/242_Libro\%2oBlanco. pdf>].

OLIVER, E.; y AGULLÓ, C. (1994): Desarrollo y educación de los niños y niñas con espina bífida. Il: la escuela infantil, Madrid, Centro de Desarrollo Curricular.

ONU (2006): Convención sobre los Derechos de las Personas con Discapacidad y Protocolo Facultativo, Nueva York, Organización de las Naciones Unidas [rhttp://www.un.org/disabilities/documents/ convention/convoptprot-s.pdf>].

PEIRÓ, J. L.; y ENCINAS, J. L. (2012): “Cirugía fetal del mielomeningocele: de los resultados experimentales a la evidencia clínica”, Cirugía Pediátrica, vol. 25, nํㅜ 1, págs. 1-3.

SUÁREZ LLORCA, C. (2003): Los alumnos con espina bífida en el contexto escolar [tesis doctoral], Alicante, Universidad de Alicante [<http://hdl.handle. net/10045/9913〉].

TIRAPU, J. et al. (2001): Déficits neuropsicológicos en la hidrocefalia asociada a espinabífida, APAFEB.

VV.AA. (2002): Desde las discapacidades hacia la inclusión. I Congreso Internacional de Discapacidad de Euskadi. XI Congreso Estatal de Espina Bífida e Hidrocefalia, Bilbao, Asociación Bizkaia Elkartea de Espina Bífida e Hidrocefalia.

VV.AA. (1983): I/ Congreso y Asamblea General Internacional de Espina Bífida e Hidrocefalia, Donostia-San Sebastián, Fondo de Documentación del SIIS. 